\title{
Exploring the adaptive experiences of children with parents of myocardial infarction: A Qualitative Study
}

Tahere Hashemifard ${ }^{1}$, Ali Akbar Vaezi ${ }^{2}$, Seyed Saeed Mazloomy ${ }^{3}$, Tahereh Kamalikhah ${ }^{4}$, Mehdi Khankolabi ${ }^{5}$, Abbas Andishmand ${ }^{6}$, Mohammad Hossein Baghianimoghadam ${ }^{7}$

${ }^{1}$ Department of Health Education and Promotion, Shahid Sadoughi University of Medical Sciences, Yazd, Iran

${ }^{2}$ Ph.D. of Nursing, Assistant Professor, Department of Nursing, Shahid Sadoughi University of Medical Sciences, Yazd, Iran

${ }^{3}$ Ph.D. of Health Education and Health Promotion, Professor, Department of Health Education and Promotion, Social Determinants of Health Research Center, School of Public Health, Shahid Sadoughi University of Medical Sciences, Yazd, Iran

${ }^{4}$ Department of Health Education and Health Promotion, Semnan University of Medical Sciences, Semnan, Iran

${ }^{5}$ Ph.D. of Health Education and Health Promotion, School of Health, North Khorasan University of Medical Sciences, Bojnurd, Iran

${ }^{6}$ Assistant Professor, Department of Medical, Shahid Sadoughi University of Medical Sciences, Yazd, Iran

${ }^{7} \mathrm{Ph}$.D. of Health Education and Health promotion, Professor, Department of Health Education and Promotion, School of Public Health Shahid Sadoughi University of Medical Sciences, Yazd, Iran

\section{Type of article: Original}

\begin{abstract}
Background: Cardiovascular diseases are the world's leading cause of mortality. These diseases are rooted in an unhealthy lifestyle. In order to confront this subject, it is essential to identify several risk factors that contribute to heart disease (HD) in people with different attitudes, values, beliefs, expectations and motivations. This study was therefore an attempt to explain the adaptive experiences of children whose parents were involved in myocardial infarction since they were more likely subjected to get the so-called disease.

Objective: To identify the risk factors and to clear ambiguity using a qualitative research method from the experiences of people at risk of the above mentioned disease.

Methods: This qualitative study was a directed content analysis. Eighteen children (above 18 years old) of parents with a history of myocardial infarction participated, and were chosen with purposive sampling and the highest diversity. Data were collected through deep and semi structure interviews based on Protection Motivation Theory (PMT) from March to November 2015, and were analyzed along with their data collection and with usage of Lundman and Graneheim method. Interviews were conducted in non-stressful conditions with a place and time agreement.

Results: During content analysis process, 220 codes were extracted. After reviewing several times and summarizing, the codes were categorized based on similarity and proportion, and finally 12 subcategories and three categories were elicited including efforts to perform self-care in order to prevent HD, poor life style as a factor not to do preventive HD and health continuation with positive changes in life style.

Conclusions: Most participants, despite intending to do self-care behaviors to prevent HD, due to factors such as time constraint, high costs, laziness, impatience and prioritizing other life affairs, did not pay attention to their health. Therefore, providing the training programs with an emphasis on life skills can play an important role in reducing perceived response cost and promoting health.
\end{abstract}

Keywords: Directed content analysis, Adaptive experience, Heart disease

\section{Corresponding author:}

Professor Dr. Mohammad Hossein Baghianimoghadam, Department of Health Education and Promotion, School of Public Health Shahid Sadoughi University of Medical Sciences, Yazd, Iran.

Tel: +989131520732, Fax: +98.2536238555, Email: Baghianimoghadam@yahoo.com

Received: January 19, 2017, Accepted: March 18, 2017, Published: July 2017

iThenticate screening: March 06, 2017, English editing: May 28, 2017, Quality control: June 16, 2017

(C) 2017 The Authors. This is an open access article under the terms of the Creative Commons Attribution-NonCommercialNoDerivs License, which permits use and distribution in any medium, provided the original work is properly cited, the use is non-commercial and no modifications or adaptations are made. 


\section{Introduction}

Forecasts suggest that by 2020 , these diseases will cause more than $75 \%$ of deaths worldwide and if the upward trends continue, by 2030, annually, around 23.4 million people worldwide will die because of cardiovascular diseases (1). Cardiovascular diseases cause $47 \%$ of deaths in Iran (2). If control of risk factors is initiated in late adolescence, development of early stage atherosclerosis will be inhibited and will eventually lead to reduction or delay in incidence of the disease (3). With certainty, it can be said that for reducing morbidity and mortality of cardiovascular diseases, one of the most effective methods is implementing health promotion intervention and educational strategies (4). Choosing the health educational model and theory is the first step in the process of designing an educational plan (5). PMT has been used for assessing effective factors in motivation and eventually, behavior (6). This theory is a preventive one, considering the necessity to recognize the viewpoints of people at risk of HD, and further qualitative methods assist the health educators to deeply comprehend the behavioral and environmental motives from people at risk' views. PMT includes two processes of threat appraisal and coping appraisal and a fear construct that the output of two processes is protection motivation and behavior. Coping appraisal emphasizes on the coping response with the health threat and factors that decrease or increase probability of selecting adaptive responses. This cognitive meditational process consists of perceived self-efficacy, response efficacy, and response costs (7). Qualitative methods value participants' views so researchers put themselves in the context of people's real life by interviewing them (8). Therefore, the interview has the capacity of description, explanation and discovery of issues from participants' perspective (9). Hence, in order to recognize and perceive various dimensions and agents affecting the phenomenon of the social process of "preventive behaviors of people at risk of HD", methods that can distinguish ideally concrete aspects from abstract concepts are required. Understanding of the mentioned process for providing new knowledge and insights, and reloading the behavior of people whose parents are involved in myocardial infarction, because they are more at risk of this disease, it is necessary through qualitative research, until their life experiences, by using an inductive approach, can be defied and through a practical and effective educational plan, practical guidance provide can for their activity.

\section{Material and Methods}

\subsection{Research design and participants}

This study was a directed content analysis qualitative research that was conducted based on PMT. Content analysis is beyond extracting factual content from context data, and can display themes and latent patterns from the content of participants' data (10). In this study, 18 children (over 18 years old) of parents with a history of myocardial infarction who, during last year, were hospitalized in hospitals affiliated to Shiraz University of Medical Sciences, were investigated.

\subsection{Selection criteria}

The inclusion criteria encompass having a parent, with history of MI, the capability to participate in interviews, aged over 18, and having at least one risk factor for HD. Exclusion criteria include having a history of HD and lack of tendency to participate in this research.

\subsection{Interviews and data collection}

Sampling was done during different hours and days of the week. In order to collect information, semi-structured and deep interviews based on PMT in different places such as hospitals, parks and health centers were used in 2015. Purposive sampling was conducted and continued until data saturation (9). Having introduced and explained the objectives of the study, the researcher conducted interviews lasting from 30 to 65 minutes in a non-stressful and private environment with a place and time agreement. . Interview questions were developed based on PMT constructs. For example, how capable do you see yourself in preventive behaviors? If you want to apply preventive behaviors of HD what would you lose? Minimal interference was done in interview trend and an attempt was made to keep the interview to the point. Data were analyzed through content analysis using the method proposed by Graneheim and Lundman and the transcript of the recorded interviews were written on the same day, and were used as the original data and reviewed several times to reach a general perception (11). Words, sentences or paragraphs that were considered as semantic units after abstraction and conceptualization were labeled by codes according to the concept behind them. The codes were compared according to their similarities and differences, and were classified with specified labels in more abstract classes. Finally, by comparing different classes with a deep, careful reflection, the content lying in data was introduced as the theme of study. The Helsinki codes were observed; the voluntariness of participation in the study, withdrawal from the study at any time, confidentiality of the information, receiving an introduction letter and legal permission (11). 


\subsection{Research ethic}

The ethics committee of Shahid Sadoughi University of Medical Sciences, Yazd, Iran approved the study and oral consent was obtained (Code: 15646).

\subsection{Accuracy, reliability, conformability, credibility, and transferability}

To ensure the accuracy and reliability of data, the scientific precision criteria in qualitative research "Guba and Lincoln" were used (12). Conformability of the findings by observing revision, credibility by prolonged engagement of the researcher with the study samples and allocating enough time for data collection and dependability were provided by giving the interviews' transcripts and the extracted codes to other participants to be confirmed. For transferability of the findings, research processes were prepared clearly and in written form and their related computer files were saved to provide follow-up feasibility of research track and population feature for others. Also, sampling technique with maximum diversity helped transferability of the findings in this study.

\section{Results}

In total, interviews with 18 children of patients with a history of myocardial infarction led to a richness of information, data saturation and data replication. The age range of participants was 21-40 years and the mean age was $27 \pm 88$ yrs. From the qualitative analysis and comparison of data, three categories and 12 subcategories emerged with categories including efforts to perform self-care for prevention of HD, poor lifestyle as a factor of neglect in doing HD preventive behaviors and sustaining health by positive changes in lifestyle (Table1).

Table 1. Process of categories formation

\begin{tabular}{|c|c|c|}
\hline Themes & Categories & Subcategories \\
\hline \multirow{4}{*}{$\begin{array}{l}\text { Perceived self- } \\
\text { efficacy }\end{array}$} & \multirow[t]{4}{*}{ Efforts to perform self-care in order to prevent HD } & Perform self-care \\
\hline & & Using stress reduction techniques \\
\hline & & Attempt to get more information \\
\hline & & $\begin{array}{l}\text { The provision of appropriate family } \\
\text { environment }\end{array}$ \\
\hline \multirow{4}{*}{$\begin{array}{l}\text { Perceived response } \\
\text { cost }\end{array}$} & \multirow{4}{*}{$\begin{array}{l}\text { Poor lifestyle as a factor of neglect in doing HD } \\
\text { preventive behaviors }\end{array}$} & Lack of planning in life affairs \\
\hline & & Costs as a factor of neglect \\
\hline & & Inappropriate attitude to life style \\
\hline & & Not enough effort to maintain health \\
\hline \multirow{4}{*}{$\begin{array}{l}\text { Response } \\
\text { effectiveness }\end{array}$} & \multirow{4}{*}{$\begin{array}{l}\text { Health continuation with positive changes in } \\
\text { lifestyle }\end{array}$} & Activity and exercise \\
\hline & & Healthy nutrition \\
\hline & & Having tranquility \\
\hline & & Tobacco cessation \\
\hline
\end{tabular}

\subsection{Efforts to perform self-care}

Self-care is a multidimensional structure that requires behaviors which are influenced by factors such as health beliefs, life situations and events. Subcategories of efforts to perform self-care included perform self-care, using stress reduction techniques, attempt to obtain more information, and the provision of appropriate family environment.

\subsubsection{Perform self-care:}

Some participants believed that they could relatively perform self-care and preventive behaviors of HD.

Behaviors that these people stated for maintaining their health included avoiding junk food, weight control, exercises, walking and making a difference in their life by spending time in nature.

"...During pregnancy I was very overweight, now I eat food like rice less and more fruits and vegetables... ". (int.8, female 25 yrs.).

\subsubsection{Using stress reduction techniques:}

In this study, stress was an issue that all participants had experienced because of life conditions, and believed that if this sense lasts too long it will endanger their physical and mental health. Some of these people tried to use some techniques to reduce their stress and mental tension."...I try to keep my distance from nagging and anxious people and instead go toward those who give positive energy...." (int.10, male $33 \mathrm{yrs.}$.).

3.1.3. Attempt to obtain more information:

The majority of participants had the necessary information and knowledge regarding HD risk factors and some had sought further information in this regard and transferred it to the others, and believed that obtaining health 
information is easily possible from different ways. "... Honestly, I'm studying a lot about HD prevention ...." (int.11, male 39 yrs.)

3.1.4. The provision of appropriate family environment:

All of the participants believed that valuing health depends on effective communication between family members, collaboration and cooperation in preventive behaviors and appropriate family situation. "...Whenever intimacy and communication between family members are more, mental concerns and the likelihood of sickness become less..." (int. 3, female 23 yrs.)

\subsection{Poor lifestyle as a factor of neglect doing HD preventive behaviors}

Subcategories of this category included lack of planning in life affairs, costs as a factor of neglect, inappropriate attitude to lifestyle and not enough effort to maintain health.

3.2.1. Lack of planning in life affairs:

In this study, most participants indicated time constrains due to job or educational conditions and also the occurrence of unexpected work as reasons not to do preventive behaviors, especially exercise and healthy diet.

"... in summer, I had sport and club plans, but when my dad had a myocardial infarction, we had to take him to the hospital and I gave up my exercise...." (int.16, female 34 yrs.).

3.2.2. Costs as a factor of neglect:

The participants believed that proper financial situation can prevent HD and have significant impact on valuing health. They reported high prices of nutritious food; seasonal fruits, check-ups and various exercises as effective factors of not making positive changes in lifestyle. "... I can't adhere to a healthy diet because of the high prices of healthy food...." (int.12, male 25 yrs.).

3.2.3. Inappropriate attitude to lifestyle:

Poor attitude of some participants or their family members towards performing healthy behaviors, caused incidence of HD risk factors and dismissal of HD preventive behaviors. "... Some of my family members say that life is too short why should we bother ourselves?; this belief itself automatically has effect on the other members...." (int. 6, female 21 yrs.).

3.2.4. Not enough effort to maintain health:

The majority of participants mentioned laziness, fatigue, impatience, and preferring other affairs to exercise as the main barriers of doing preventive behaviors." ... Sometimes I wonder if I stay at home and do sewing or cooking, would it be better for me than doing exercise? ..."(int. 5, female 40 yrs.). "...Regular walking is boring and monotonous for me...." (int.9, male 28 yrs.).

\subsection{Health continuation with positive changes in lifestyle}

"Lifestyle" is a collection of health-related factors; nowadays following a healthy lifestyle is the most important principle in achieving health and longevity which has significant influence on maintaining and promoting people's health and on disease control and prevention. Subcategories of this category included activity and exercise, healthy nutrition, tobacco cessation, having tranquility

3.3.1. Activity and exercise:

In terms of exercise and its effects on health and HD prevention, participants cited boost in morale, increased body resistance to disease, increase of human patience and endurance, weight control and prevention of arteriosclerosis. "... I go mountain climbing at least twice a week and do light exercise that raises my heart rate in the morning because it has a positive effect on my physical and mental health...." (int. 10, male 33 yrs.)

3.3.2. Healthy nutrition:

All participants believed that a healthy diet is the way to achieve physical health and longevity, although it is not ineffective in mental health. "... I do not eat fast food or byproducts at all because it is the only fat that remains in the body for at least six months. These foods result in shortening the human life expectancy...." (int.11, male 39 yrs.).

3.3.3. Tobacco cessation:

The majority of participants were educated, and so were aware of the consequences of smoking and hookah and also the positive effects of quitting them."...When my mother had plaque and open-heart surgery, we broke the hookah pipe. It keeps my mum's heart rate down. It stops my mum's heart rate from going up...." (int. 4, female 40 yrs.).

3.3.4. Having tranquility:

Participants considered tranquility as a factor in adherence to diet, regulation of heart beat and blood pressure, increased body resistance, disease prevention, as well as resistance to life's problems."...When I am calm and feel relaxed I care more about my health and behaviors that are associated with health...." (int.8, female 25 yrs.). 


\section{Discussion}

To identify the result of this research, coping appraisal process of PMT has been used. This process consists of perceived self-efficacy, response efficacy, and response costs. The category associated with self-efficacy is "efforts to perform self-care in order to prevent HD". Self-care is a multidimensional structure that requires behaviors which are influenced by factors such as health beliefs, life situations and events (13). In this study, number of participants were more or less sure about their ability to perform self-care behaviors such as adhering to diet, walking, doing the exercise, checkup, especially in an emergency and avoiding tobacco. This concept points to self-efficacy which means confidence of the person in their ability to begin a new or difficult behavior. Some studies have investigated self-efficacy as an important factor in improving self-care and as a modifier of coronary artery disease (14). In a study conducted by Sung, negative correlation was found between self-care behavior and health maintenance with risk factors of cardiovascular disease (15). But in the study done by Chen and Al-Khawaldeh strong correlation has been proved between self-efficacy and self-care behavior $(16,17)$. The results of a study by Khosravi Zade and colleague, showed that self-efficacy based training can lead to an increase in self-care behaviors such as reducing salt intake and weight control (18). Regarding stress and stress management, participants acknowledged that stress and psychological pressures are the most important factors in HD development and have an adverse impact on their self-care behavior. Parents heart disease, concerns about leaving them alone at home, economic problems, employment status and student conditions were stated as the reasons for participants' stress. In one study, it was shown that stress affects development of HD directly and its risk factors included poor nutrition, low physical activity, smoking and alcohol consumption indirectly (19). In this study, some participants tried to apply coping strategies such as relaxation exercises, being located in a quiet environment, spending time in nature, sociability with family, friends and positive people, giving positive suggestions to their own and adherence to religious values in order to be relaxed and control themselves. Improvement in stress management in the form of meditation and yoga are associated with reduction in risk factors of cardiovascular diseases such as weight loss, total cholesterol, cholesterol with high density (for men), triglycerides, Hbalc (for diabetics) and reductions in hostile feelings (20). Therefore, teaching stress management techniques and strategies to adolescents and youth, can promote their selfefficacy, mental health and consequently can reduce the risk of HD. Regarding knowledge acquisition of HD, although most participants had good information about preventive behaviors of HD because of existence of factors such as time constraint, laziness, impatience and prioritizing other life affairs, they acted poorly in terms of self-care due to the previously mentioned barriers. It can be justified since the majority of participants were educated, had good knowledge and information, but knowledge alone cannot have an impact on performance and as a result, cannot have an impact on self-care of individuals. This finding is consistent with the result of Kang's study (21). Concerning the subcategory of provision of appropriate family environment to prevent and control HD, factors that participants indicated as suitability of the family environment and were recognized as one of the most important factors regarding health were intimate relationship between family members and receiving psychological support from them. What is clear, is that the individual perception of availability of social support and personal satisfaction that one acquires in communication with others can make obstacles against disease and mental pressure. Cares and emotional connections created by social support can be very effective in health and Longevity (22). In Mendis and Cole's study it was also shown that receiving positive support from family, friends and peers can facilitate lifestyle changes $(23,24)$. The results of that study are consistent with the results of our study. The category associated with perceived response cost construct is poor lifestyle as a factor of less attention to preventive behaviors. Lifestyle includes activities and attitudes that can affect a person's health. Appropriate food habits, stress management, physical activity and smoking cessation are the most important aspects of a healthy lifestyle (25). Continuous existence of healthy lifestyle factors are accompanied with reduction in risk of myocardial infarction and its mortality (26). In this category, one of the subcategories was lack of planning in life. Existence of factors such as time constraint due to job or educational conditions, having familial responsibilities, the occurrence of unexpected work and easy access to fast food were indicated as the most important factors of less attention to performing behaviors such as exercise and adhering to appropriate diet regime by the participants. The interesting point is that in the age group of youth, due to their certain cultural, social and economical situation which was student or employed and with most of their time spent away from home and according to the problems of transportation and traffic which stems from urbanization, they have to eat at least one meal a day away from home and consume a variety of convenience foods (27). In a study conducted by Keeler in female university students, it was revealed that time constraint for preparing healthy food and easy access to unhealthy food substances are barriers to a healthy diet (28). In other studies time constraint is also introduced as one of the factors of less attention to exercise and dietary adherence $(29,30)$. Usually, the first and simplest reason for inactivity and lack of participation in exercises and consumption of unhealthy food is time constraint. The best recommendation for overcoming this obstacle is acquisition of time management skills. If these people are provided a good plan they will be able to exercise and 
prepare healthy food in their free time. In this category, one of the factors of neglect in doing preventive behaviors was cited as cost of doing exercise (31) and seasonal fruits. The studies showed that the consumption of fruit and vegetables is more expensive than other foodstuffs and the need to buy fresh fruit and vegetables every few days continuously is also a barrier of a healthy diet (32). Ashton's study showed the cost of unhealthy food is less than healthy food (30). Inappropriate attitude to life is another subcategory of poor lifestyle. The most important barriers related to this subcategory are, having myths and wrong beliefs in health maintenance styles such as achievement of tranquility by smoking and usefulness of solid oil. In this study, people with lower education and self-employment had positive attitude towards smoking and its effect, this subject suggests that low education levels have caused lower knowledge of the fatal complications of smoking. Conducted investigations also showed that participants, to achieve tranquility and reduce life stress tend to smoke, that confirms the results of the present study $(33,34)$. Hence, in order to create awareness and improve attitude towards healthy lifestyle, and as a result, create positive behavioral changes, eliminating the leading cause of creating poor attitude and implementation of educational programs of life skills have an important role. Not enough effort to maintain health was another subcategory of poor life style category. In this regard, the most important factor mentioned was laziness and impatience. In Kumer's study laziness was stated as one of the obstacles of physical activity (35). The category associated with the response efficacy construct is health continuation with positive changes in lifestyle. From the participants' perspective, positive changes in lifestyle cause increased body resistance, longevity, disease prevention, health and vitality of the individual. Results of a prospective study conducted on young people aged 18-30 showed that healthy lifestyle changes are accompanied by risk reduction and unhealthy lifestyle changes are associated with an increased risk of atherosclerosis in middle age (36). Based on the results of one study, a small improvement in changes in lifestyle can lead to significant reduction in incidence of myocardial infarction (37). In general, the results of the literature reviews offer an overall view of the longitude relationship between physical activity and the incidence of noncontagious diseases and health problems. It seems that physical activity is a contributing factor to prevent agerelated diseases. Inactivity and unhealthy food habits are related to weight gain, obesity, and becoming overweight, and are a major cause of modern disease such as coronary heart disease or diabetes type 2 (38).

\section{Conclusions}

The result of this study showed that most of the participants were sure of their ability of preventive behavior about HD and knew about these positive effects. But because of issues like inappropriate attitude to life style, lack of planning in life affairs, didn't make such positive changes in their life. The practical importance of these results is that, based on our finding, since the unhealthy lifestyle is formed at an early age and remains stable during the next years, before consolidation and formation of these habits, necessary actions must be taken for following a healthy lifestyle, and parents should put the necessary education available for their children from early childhood, because the later attempts to change established habits will be very difficult and perhaps impossible.

\section{Acknowledgments:}

This article is a part of the author's Ph.D. thesis of first author in health education and health promotion. Therefore, the authors wish to thank the authorities of Yazd University of Medical Sciences and all those who helped us in this research. The study received no grant from any government or nongovernmental institution.

\section{Conflict of Interest:}

There is no conflict of interest to be declared.

Authors' contributions:

All authors contributed to this project and article equally. All authors read and approved the final manuscript.

\section{References:}

1) Gaziano TA, Bitton A, Anand S, Abrahams-Gessel S, Murphy A. Growing epidemic of coronary heart disease in low-and middle-income countries. Curr Probl Cardiol. 2010; 35(2): 72-115. doi: 10.1016/j.cpcardiol.2009.10.002. PMID: 20109979, PMCID: PMC2864143.

2) Samiee Rad F, Ziaee A, Qambarian A, Mirmiran P, Momenan A, Azizi F. Association between risk factors of cardiovascular diseases and obesity among Tehranian women: Tehran Lipid and Glucose Study. Iran J Endocrinol Metab. 2012; 14(2): 101-8.

3) McMahan CA, Gidding SS, McGill HC. Coronary heart disease risk factors and atherosclerosis in young people. J Clin Lipidol. 2008; 2(3): 118-26. doi: 10.1016/j.jacl.2008.02.006. PMID: 21291730. 
4) Hazavei MM, Shahbadi S, Hashemi SZ. The role of health education in reducing cardiovascular diseases risk factors: a sysytematic review. Knowledege and Health. 2014; 9)1): 30-42.

5) Heydar Nia AR. Issues in the health education process. Tehran: Zamani publisher; 2002.

6) Morowatisharifabad MA, Jowzi F, Barkhordari Firozabad A, Falahzadeh H. Related factors to workers' use of hearing protection device in knitting \& ppinning factories of Yazd city based on Protection Motivation Theory. Int J Occup Hyg. 2009; 6(3): 47-54.

7) Cismaru M, Dshpande S, Thurmeier R, Lavak AM, Agrey N. Prevention fetal alcohol Spectrum disorder: The role of protection motivation. Health Mark Q. 2010; 27(1): 66-85. doi: 10.1080/07359680903519776. PMID: 20155551.

8) Lindberg C, Lewis-Spruill C, Crownover R. Barriers to sexual and reproductive health care: urban male adolescents speak out. Issues Compr Pediatr Nurs. 2006; 29(2): 73-88. doi: 10.1080/01460860600677577. PMID: 16772237.

9) Adib Hajbagheri M, Parvizi S, Salsali M. Qualitative research methods. Tehran: Booshra Publication; 2004.

10) Spannagel C, Gläser Zikuda M, Schroeder U. Application of qualitative content analysis in user-program interaction research. Forum Qual Soc Res. 2005; 6(2): 29.

11) Graneheim UH, Lundman B. Qualitative content analysis in nursing research: concepts, procedures and measures to achieve trustworthiness. Nurse Educ Today. 2004; 24(2): 105-12. doi: 10.1016/j.nedt.2003.10.001. PMID: 14769454.

12) Hsieh HF, Shannon SE. Three approaches to qualitative content analysis. Qual Health Res. 2005; 15(9): 1277-88. doi: 10.1177/1049732305276687. PMID: 16204405.

13) Stys AM, Kulkarni K. Identification of self-care behaviors and adoption of lifestyle changes result in sustained glucose control and reduction of comorbidities in type 2 diabetes. Diabetes Spectrum. 2007; 20(1): 55-8. doi: 10.2337/diaspect.20.1.55.

14) Hoseinzadeh T, Paryad A, Asiri Sh, Kazemnezhad L. Relationship between perception of illness and general self-efficacy in coronary artery disease patients. Holist Nurs Midwifery J. 2012; 22(1(67)): 1-8.

15) Sung K. The Effects of Elderly Diabetes Mellitus Patients' Self-care Behavior and Health Conservation on Cardiovascular Risk Factors. J Korean Acad Community Health Nurs. 2015; 26(2): 150-9. doi: 10.12799/jkachn.2015.26.2.150.

16) Chen AM, Yehle KS, Albert NM, Ferraro KF, Mason HL, Murawski MM, et al. Relationships between health literacy and heart failure knowledge, self-efficacy, and self-care adherence. Res Social Adm Pharm. 2014; 10(2): 378-86. doi: 10.1016/j.sapharm.2013.07.001. PMID: 23953756, PMCID: PMC3923851.

17) Al-Khawaldeh OA, Al-Hassan MA, Froelicher ES. Self-efficacy, self-management, and glycemic control in adults with type 2 diabetes mellitus. J Diabetes Complications. 2012; 26(1): 10-6. doi: 10.1016/j.jdiacomp.2011.11.002. PMID: 22226484.

18) Khosravizade A, Hassanzadeh A, Mostafavi F. The impact of self-efficacy education on self-care behaviours of low salt and weight setting diets in hypertensive women covered by health-care centers of Dehaghan in 2013. J Pak Med Assoc. 2015; 65(5): 506-11. PMID: 26028385.

19) Chandola T, Britton A, Brunner E, Hemingway H, Malik M, Kumari M, et al. Work stress and coronary heart disease: what are the mechanisms? Eur Heart J. 2008; 29(5): 640-8. doi: 10.1093/eurheartj/ehm584. PMID: 18216031.

20) Daubenmier JJ, Weidner G, Sumner MD, Mendell N, Merritt-Worden T, Studley J, et al. The contribution of changes in diet, exercise, and stress management to changes in coronary risk in women and men in the multisite cardiac lifestyle intervention program. Ann Behav Med. 2007; 33(1): 57-68. doi: 10.1207/s15324796abm3301_7. PMID: 17291171.

21) Kang Y, Yang IS. Cardiac self-efficacy and its predictors in patients with coronary artery diseases. J Clin Nurs. 2013; 22(17-18): 2465-73. doi: 10.1111/jocn.12142. PMID: 23441807.

22) Hatami H, Razavi S, Eftekhar H, Majlesi F. Comprehensive book of public health. Tehran: Arjemand Publications. 2007; 45-7.

23) Mendis K, Forster T, Paxton K, Hyland K, Yelverton J, McLean R, et al. Large and forgotten in rural Australia: assessment, attitudes and possible approaches to losing weight in young adult males. BMC public health. 2014; 14: 243. doi: 10.1186/1471-2458-14-243. PMID: 24612872, PMCID: PMC4008138.

24) Cole JA, Smith SM, Hart N, Cupples ME. Do practitioners and friends support patients with coronary heart disease in lifestyle change? A qualitative study. BMC Fam Pract. 2013; 14: 126. doi: 10.1186/1471-229614-126. PMID: 23984815, PMCID: PMC3765931. 
25) Kamrani Rad Z, Attarian F, Ebrahimi pour H. Health-promoting lifestyle among Mashhad School of Health Students, Mashhad, Iran, 2014. J midwife Reprod Health. 2014; 2(3): 195-204. doi: 10.22038/JMRH.2014.2918.

26) Khaw KT, Wareham N, Bingham S, Welch A, Luben R, Day N. Combined impact of health behaviours and mortality in men and women: the EPIC-Norfolk prospective population study. PLoS Med. 2008; 5(1): e12. doi: 10.1371/journal.pmed.0050012. PMID: 18184033, PMCID: PMC2174962.

27) Ramezani Tehrani F, Farahmand M, Amiri P, Paikari N, Azizi F. Women's Perception Regarding to Healthy Nutrition Inhibitors: A Qualitative Research in Tehran Lipid and Glucose Study (TLGS). Iran J Endocrinol Metab. 2011; 13(1): 48-57.

28) Keeler LA, Clifford DE, August B, Kowalski P, Morris MN. Examination of a peer-led, non-diet nutrition and exercise adherence pilot program on a college campus: FitU. Manuscript submitted for publication. 2013; 11(1): 84.

29) Korkiakangas EE, Alahuhta MA, Husman PM, Keinänen - Kiukaanniemi S, Taanila AM, Laitinen JH. Motivators and barriers to exercise among adults with a high risk of type 2 diabetes - a qualitative study. Scand J Caring Sci. 2011; 25(1): 62-9. doi: 10.1111/j.1471-6712.2010.00791.x. PMID: 20384973.

30) Ashton LM, Hutchesson MJ, Rollo ME, Morgan PJ, Thompson DI, Collins CE. Young adult males' motivators and perceived barriers towards eating healthily and being active: a qualitative study. Int J Behav Nutr Phys Act. 2015; 12(1). doi: 10.1186/s12966-015-0257-6.

31) Salahshuri A, Sharifirad G, Hassanzadeh A, Mostafavi F. Physical activity patterns and its influencing factors among high school students of Izeh city: Application of some constructs of health belief model. J Educ Health Promot. 2014; 3: 25. doi: 10.4103/2277-9531.127618. PMID: 24741665, PMCID: PMC3977392.

32) Stephens T, Troutman A, Johnson L, Taylor T. Barriers to Fresh Fruit and Vegetable intake among African Americans in a Southeastern City: Preventive Implications for Cardiovascular Disease. J Fam Med Dis Prev. 2015; 1: 1. doi: 10.23937/2469-5793/1510003.

33) Kaai SC, Manske SR, Leatherdale ST, Brown KS, Murnaghan D. Are experimental smokers different from their never-smoking classmates? A multilevel analysis of Canadian youth in grades 9 to 12 . Chronic Dis Inj Can. 2014; 34(2-3): 121-31. PMID: 24991775.

34) Mohammadnezhad M, Tsourtos G, Wilson C, Ratcliffe J, Ward P. "I have never experienced any problem with my health. So far, it hasn't been harmful": older Greek-Australian smokers' views on smoking: a qualitative study. BMC public health. 2015; 15: 304. doi: 10.1186/s12889-015-1677-6. PMID: 25885899, PMCID: PMC4391085.

35) Kumar J. Identifying barriers to healthy eating and physical activity in a low-income community in southwestern Kansas: Kansas State University; 2014.

36) Spring B, Moller AC, Colangelo LA, Siddique J, Roehrig M, Daviglus ML, et al. Healthy lifestyle change and subclinical atherosclerosis in young adults: Coronary Artery Risk Development in Young Adults (CARDIA) study. Circulation. 2014; 130(1): 10-7. doi: 10.1161/Circulation.113.005445. PMID: 24982115, PMCID: PMC4615574.

37) Kulshreshtha A, Vaccarino V, Judd SE, Howard VJ, McClellan WM, Muntner P, et al. Life's Simple 7 and Risk of Incident Stroke The Reasons for Geographic and Racial Differences in Stroke Study. Stroke. 2013; 44(7): 1909-14. doi: 10.1161/STROKEAHA.111.000352. PMID: 23743971, PMCID: PMC3816734.

38) Reiner M, Nierman C, Jekauc D, Woll A. Long-term health benefits of physical activity-a systematic review of longitudinal studies. BMC Public Health. 2013; 13(1): 813. doi: 10.1186/1471-2458-13-813. 